during its detention, and before it reaches the cylinder, unless, in fact, the heat abstracted in condensation be restored to it, the loss of power is very great. This has hitherto been the stumbling.block of compressed air engines, and M. Mékarski seems to have completely met the difficulty. He adopts as a re-heater a cylinder holding about roo litres of water, taken from the boiler of an engine, at five atmospheres, and to obtain the maximum of effect possible, the condensed air is delivered from the reservoirs to the cylinder only after traversing the entire mass of water.

By a clever contrivance $M$. Mékarski regulates at pleasure the action of the compressed air upon the piston. Two hermetically-closed boxes are placed vertically upon the re-heater; their common face is formed by a caoutchouc diaphragm, in direct connection with an obturator, which opens or shuts more or less the opening which communicates between the lower box and the chamber containing a mixture of compressed air and vapour in the upper part of the hot-water cylinder. It will be seen that this orifice will be more or less uncovered according as the pressure in the lower box will be above, or not, the pressure in the lower box. This second box is itself filled with air, and constitutes a small pump-barrel, in which a large plunger piston works. The rod of the piston is a screw, and is fitted outside with a small regulator, on which the driver works. This may rapidly be made to vary the presence of the air in the upper box, and consequently the pressure be increased or diminished of the air which is delivered from the lower box to the motory cylinder.

\section{THE GREAT TELESCOPE OF THE PARIS ORSERVATORY}

$\sqrt{\mathrm{L}} \mathrm{L}$ have from time to time noted the progress of the great telescope which for years has been in course of construction for the Paris Observatory, and now that it is completed and in its place we are glad to be able to present a view of the instrument, for which, and for the details which follow, we are indebted to $L a$ Nature.

In $1855 \mathrm{M}$. Le Verrier purchased in England two large discs, the one of flint and the other of crown glass, intended to form the material for an object-glass. The late Léon Foucault, the eminent physicist of the Observatory, was charged with the investigation of the processes which should be employed to cut these large glasses, whose dimensions were much greater than those to which opticians had been accustomed. It is known how Foucault was led, by his series of investigations, to malse mirrors of silvered glass. Successive attempts enabled him to present French observatories with reflectors of 40 , of 50 , and finally of 80 centimetres in diameter, having a tube in length only six times the diameter of the mirror. The largest of the telescopes constructed by Foucault himself, of 80 centimetres aperture, is at Marseilles, under the care of M. Stephan ; by means of it this astronomer has seen all that Herschel saw with his enormous metallic reflector of $I^{*} 45 \mathrm{~m}$. diameter, all that Lord Rosse has been able to see with his leviathan of I "7o m., and he has added hundreds of new nebulæe to the list given by his illustrious predecessors.

To crown his labours, L. Foucault wished to construct the largest mirror which it would be possible to make by his admirable method. This superior limit is $\mathrm{r} 20 \mathrm{~m}$. diameter. M. Le Verrier caused to be cast at St. Gobain a block of glass weighing 700 kilogrammes, which was rough-ground and shaped in the workshops of MM. Sauter and Lemonnier. But to construct this telescope, with its tube of 16 metres in length, required special funds, the ordinary budget of the Observatory not being sufficient. M. Le Verrier sought to obtain them from the Corps Législatif, which, in 1865 , voted a sum of 400,000 francs.

By the beginning of 1868 , Foucault, notwithstanding his researches on regulators and the fatigue caused by the active part he took in the Exposition of 1867 , had prepared the plans for the large reflector, when death snatched him from his work, and deprived France of one of the most original and finest geniuses she has possessed. This fatality, and the troubles which soon after and for long disturbed the Observatory, seemed to have lost to the country the work of years, and to have rendered useless the liberality of Government. Happily, the Minister of Public Instruction, M. Duruy, was willing to lend an attentive ear to the suggestions of men of science, and place at their service an intelligence eager for progress. At the request of the friends of Foucault he ordered the work which had been begun to be continued, and the authorities of the Observatory eagerly complied with his orders. An eminent mechanician, M. Eichens, indicated to $M$. Le Verrier by the Grand Prize in Mechanics which he obtained at the Exposition of 1867 , and by his construction of large instruments for the Observatory, received the order for the construction of the telescope. $M$. Adolphe Martin, whom Foucault had instructed in his methods and associated with himself in his optical undertakings, was charged with the polishing of the mirror. Finally, M. Le Verrier entrusted to one of the astronomers of the Observatory, M. Wolf, the general superintendence of the work.

The construction ought to have been completed in three years. The war and the changes in the Observatory caused the work to languish, and it was not resumed with vigour until the return of M. Le Verrier as Director in 1873. At the commencement of 1875 the mirror was completed and tried upon terrestrial objects; $M$. Wolf had got a shelter constructed for the telescope and the staircase for the observer; finally, in the month of October, M. Eichens sent in the instrument complete in all its main details.

The total cost of the instrument and of the observatory amounts to 190,000 francs.

The illustration which we give represents the telescope in a position for observation. The wheeled hut under which it usually stands, a sort of wagon seven metres high by nine long and five broad, is pushed back towards the north along double rails. The observing staircase has been fitted to a second system of rails, which permit it to circulate all round the foot of the telescope, at the same time that it can turn upon itself, for the purpose of placing the observer, standing either on the steps or on the upper balcony, within reach of the eye-piece. This eye-piece itself may be turned round the end of the telescope into whatever position is most easily accessible to the observer.

The tube of the telescope, 7.30 metres in length, consists of a central cylinder, to the extremities of which are fastened two tubes of 3 metres long, consisting of four rings of forged iron bound together by twelve longitudinal bars also of iron. The whole is lined with small sheets of steel plate. The total weight is about 2,400 kilogrammes. At the lower extremity is fixed the barrel which holds the mirror; at the other end a circle, movable on the open mouth of the telescope, carries at its centre a plane mirror, which throws to the side the cone of rays reflected by the great mirror. The telescope is thus on the Newtonian system. That of Melbourne, so admirably constructed in England, is a Cassegrain telescope; the metallic mirror is pierced at its centre by an aperture which receives the eye-piece, a system so far advantageous that the observer always remains at the lower part of his instrument, and has to raise himself only a very short distance above ground, but less calculated perhaps to produce a perfect image than the Newtonian system adopted by Foucault.

The weight of the mirror in its barrel is about 800 kilogrammes; the eye-piece and its accessories have the same weight. Such is the load under which the tube of 


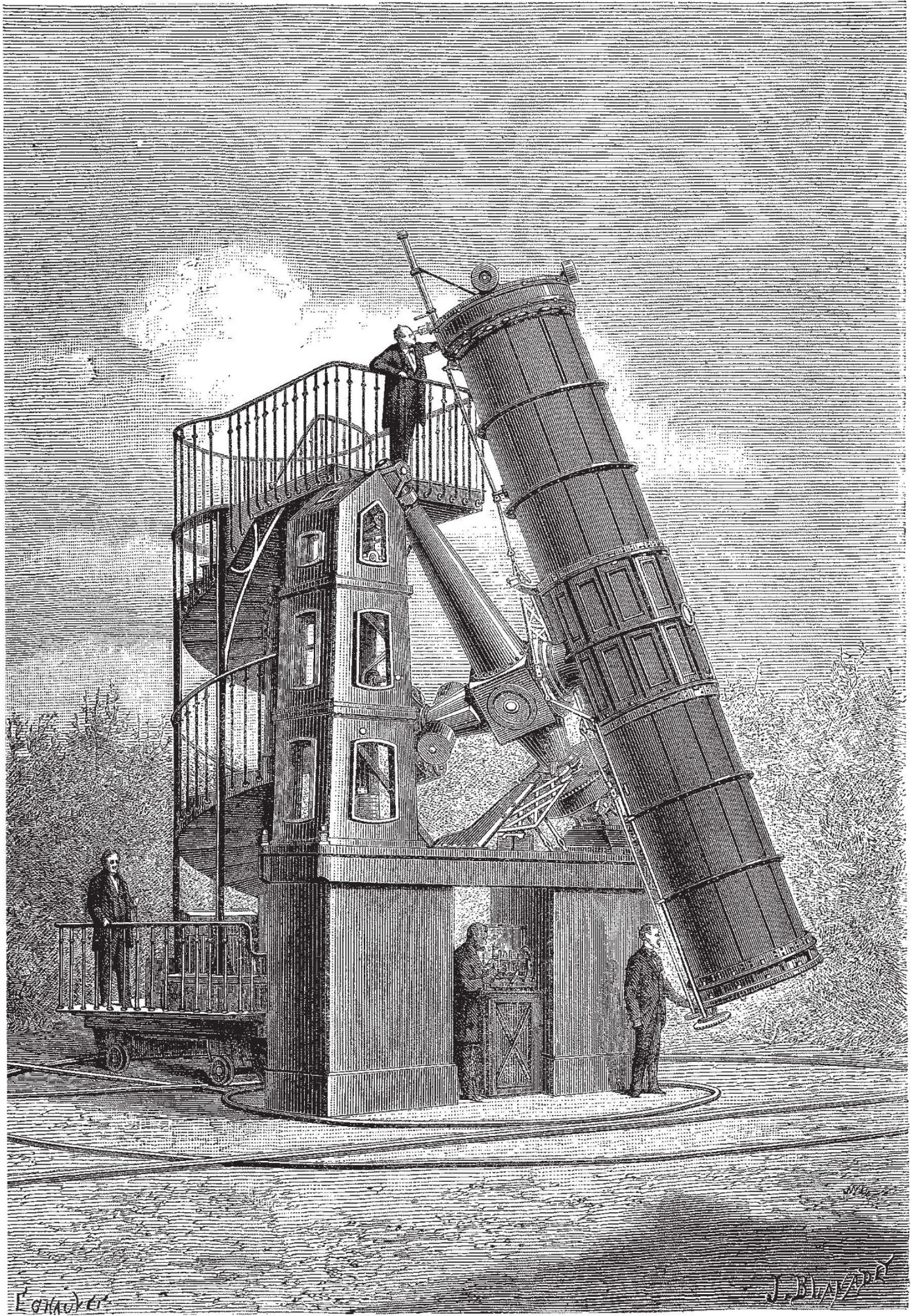


the telescope, suspended by its centre, must not bend more than a millimetre in the most unfavourable positions, according to the calculations by which $\mathrm{M}$. Wolf determines its dimensions. Experience has verified his calculations; the two mirrors remain exactly centred upon each other in all positions of the telescope.

It is necessary, however, to be able to direct the tube toward any point of the sky, and it is necessary, moreover, that when the star is once in the field of the instrument, that should be able to follow it, by a simple movement, in its apparent course through the heavens. This is accomplished by what is called the equatorial mounting of the telescope. This revolves on an axis, cast of iron and steel, whose direction is parallel to the axis of the celestial sphere. Then it may be inclined more or less on this axis, by turning round in a second axis of steel, which crosses the former at a right angle, and partakes in its movement of rotation. The whole of the arrangement of double axes, a veritable wonder of mechanism, from the precision and ease of the movement, weighs with the telescope 10,000 kilogrammes. Such is the mass which, like the hand of a gigantic chronometer, must follow with precision the march of the stars in the vault of heaven, obedient to the action of clockwork, controlled by a Foucault regulator.

To realise this wonder, M. Eichens had to put together the most delicate apparatus of the mechanics of precision, and, preserving their delicacy intact, give them the strength necessary to support great weights. We cannot explain in detail the series of these wonders, tell how friction is almost annihilated throughout, how all the parts are in equilibrium, whatever be the position of the telescope: how, in fine, at the same time that the instrument follows the movement of the sky, the observer may at his pleasure move it with perfect ease in all directions by means of contrivances placed at his hand.

The perfection of mechanism would be nothing if it did not serve the purpose of observing the stars with an optical apparatus of equal perfection. Let us at once say that the first attempts which have been made with the instrument have completely satisfied the astronomers. Not only has the mirror acquired, under the hand of $M$. Martin, the rigorously parabolic form which gives it the property of collecting in a single point the rays of a star, but the very complex eye-piece, by means of which the luminous point is observed, is itself without a single defect. It now only remains to silver the surface of the mirror, an operation at present easy, by the processes of M. Ad. Martin, and which will be accomplished in a large dish I'30 metres in diameter. Meantime, the surface of the polished glass reflects sufficient light to make it possible to observe the most feeble stars; directed towards the moon, the telescope concentrates in the eye a light almost intolerable. It may be judged from this what will be the brilliancy of celestial images when the silvered mirror will throw upon the eye, not merely scarcely one-half, but more than nine-tenths of the light which it receives.

The comparison which we made above between the Marseilles telescope of 0.80 metre aperture and the most powerful instruments elsewhere, allows us to predict the results which science has a right to expect from a telescope whose mirror is greater by half, and whose mechanism has reached the latest limits of perfection. M. Wolf, to whom the use of the telescope has been entrusted, proposes to employ it in observing the planets and their satellites. At the same time the new telescope will be fitted with all the apparatus necessary for photography and the spectroscopic observation of the stars. It should be remembered, however, that the use of such a gigantic instrument requires a long apprenticeship; the Melboume instrument had two observers before it came into the hands of an astronomer who knew how to make good use of it.
In a few weeks will be completed the first of the great instruments promised to France by MM. Le Verrier and Foucault. The construction of the telescope has been undertaken first, that it may serve as a study for the construction, much more delicate, of the great refractor of I6 metres in length, with an object-glass of 75 metre aperture. The success of the reflector is a guarantee that M. Le Verrier, with his eminent colleagues, will accomplish satisfactorily the second part of his great and patriotic enterprise.

\section{THE LOAN EXHIBITION OF SCIENTIFIC \\ APPARATUS AT SOUTH KENSINGTON}

$\mathrm{N}$ the 3 rd inst., as we have already intimated, Her Imperial Highness the Crown Princess of Germany invited to her palace forty of the representatives of science of Berlin, to lay before them the plan of the London Exhibition of Scientific Apparatus, and to ask their co-operation for this purpose. Amongst those honoured by invitations were the Ministers of Education and of Commerce, the Postmaster-General, and the following professors of the University :- $M M$. Braun (botanist), Dove, Helmholtz, and Kirchhoff (physicists), Du Bois-Reymond (physiologist), Kiepert (geographer), Förster (astronomer), Peters (zoologist), Kronecker (mathematician), Websky (mineralogist), Hofmann, Oppenheim, and Sell (chemists), Wichelhaus (technologist). Orta (agriculturist); the following professors of the Polytechnic School :-MM. Reulaux (mechanician), Liebermann (chemist), Vogel (photographer), and Scheibler (agricultural chemist); the director of the South Kensington Museum, Mr. Cunliffe-Owen, the directors of the German Industrial Museum, MM. Gruner and Lessing, the manufacturers, Dr. Werner Siemens (member of the Academy), and Dr. Martius. The illustrious hostess, as well as His Imperial Highness the Crown Prince, pleaded warmly for the worthy representation of Germany in the London Exhibition. Although the short time left for preparation, and the coincidence of the exhibition with that of Philadelphia, were generally felt as serious drawbacks, some of the men of science present taking the lead assembled the following day, when a general committee was formed under the presidency of Dr. A. W. Hofmann ; with the view of forming special committees for the different branches of the exhibition, and of inviting one member of every German University and Polytechnic School to co-operate with them. An invitation to the men of science and the manufacturers of scientific apparatus has already been issued.

"Science," the invitation says, "being the common property of all nations, the exhibition of the appliances by which it is promoted partakes of an international character. The objects pursued by the English Cormmission in organising the Exhibition have in Germany also been recognised as worthy of attainment, and, in order to give an impulse in our Fatherland to German participation in the Exhibition, a Committee has been formed, at the special instance of the Crown Prince and Princess of Germany, which has been intrusted by the English Commission with the collection and selection of objects worthy of being exhibited."

The invitation then proceeds to detail the conditions of exhibition settled by the Science and Art Department, and concludes as follows:-

"The Exhibition of Scientific Apparatus in London essentially differs from the former Exhibitions, as it pays less regard to merely commercial interests, but keeps in view the higher aim of disseminating as widely as possible the knowledge of the different methods of science. In order to render full justice to this task, the British Governrnent (Science and Art Department) will bear all the c ssts of packing, sending, and returning any objects that may be confided to its care." 